\title{
Comparação da Taxa e Eficiência de Deposição entre os Consumíveis ER70S-6 e E71T-1C
}

\author{
Jaime Casanova Soeiro Juniorr ${ }^{1}$, Mauro Apolinário da Luz ${ }^{1}$, Sérgio Duarte Brandi ${ }^{1}$ \\ 1 Departamento de Engenharia Metalúrgica e de Materiais, Escola Politécnica, Universidade de São Paulo, São Paulo, SP, Brasil.
}

Recebido: 07 Dez., 2014

Aceito: 29 Jan., 2015

E-mails:

soeirojunior.jc@gmail.com (JCSJ), mapoliluz@uol.com.br (MAL), sebrandi@usp.br(SDB)
Resumo: Na soldagem de aço de baixo carbono podem ser empregados diversos consumíveis, como o arame tubular e o arame maciço. Este trabalho compara a taxa e a eficiência de deposição em função da corrente de soldagem, da distância do bico de contato à peça (DBCP) e do tipo de gás de proteção, comparando-se o ER70S-6 com o E71T-1C. As taxas de deposição foram medidas usando-se uma sequência de cordões de solda sobre chapa de aço. As frequências de destacamento das gotas foram medidas a partir de equipamento de aquisição de dados, baseando-se nas variações de tensão do arco. O diâmetro da gota foi calculado teoricamente com base na velocidade de alimentação do arame. Foi utilizado um programa para análise estatística dos resultados produzidos pelos experimentos. Os resultados mostraram que a taxa de deposição aumenta com o aumento da corrente e com o aumento da DBCP. Da mesma maneira, a variável mais importante para controlar a eficiência de deposição foi a natureza do consumível. O ER70S-6 apresentou uma maior eficiência de deposição que o arame tubular E71T-1C, como era esperado, uma vez que o arame tubular gera escória que não é contabilizada na massa do cordão depositado.

Palavras-chave: MIG/MAG; Arame tubular; ER70S-6; E71T-1C; Taxa de deposição; Eficiência de deposição.

\section{Comparison of Deposition Rate and Deposition Efficiency between ER70S-6 and E71T-1C Consumables}

\begin{abstract}
In welding of low carbon steel, various consumables types can be employed. Among them, flux cored wire and solid wire have great application potential and substitution toward other consumables like coated electrode. This paper compares the deposition rate, the deposition efficiency, the frequency of detachment of the drop of molten metal addition and the diameter of the droplet of molten filler metal, as a function of welding parameters such as welding current, contact tip to work distance (CTWD), and the type of shielding gas, comparing the ER70S- 6 with the E71T-1C filler metal. Deposition rates were measured using a sequence of three welds performed in bead on plate on ASTM A36 steel plate. The frequencies of filler metal droplets were computed from data acquisition equipment, based on variations of arc voltage. The drop diameter was theoretically calculated based upon the wire feed speed. For data analysis, a program for statistical analysis of the results produced by the experiments was used, which allowed to determine up to the second order interactions between the studied parameters. The results of the experiments show that the deposition rate increases with increase in current and with increase in CTWD. Likewise, the most important factor to control the deposition efficiency was the type of the consumable. The ER70S- 6 presented a higher deposition efficiency than the flux cored wire E71T-1C, as expected, since the flux cored wire produces slag, which is not take into account in the mass of deposited bead.
\end{abstract}

Key-words: GMAW; FCAW; ER70S-6; E71T-1C; Deposition rate; Deposition efficiency.

\section{Introdução}

Os processos de soldagem arame tubular e MIG/MAG são muito semelhantes em seus princípios de funcionamento e nos tipos de equipamentos utilizados. Ambos são processos de soldagem por fusão, com arame alimentado de forma contínua e o arco elétrico sendo estabelecido entre o eletrodo e a peça, podendo ser protegido por gás de proteção (arame maciço e arame tubular com proteção gasosa) ou não (arame tubular auto protegido). Para ambos os processos os equipamentos são os mesmos, exceto a 
roldana para alimentação do arame, onde é recomendada a roldana recartilhada para o arame tubular e a roldana lisa para o arame maciço [1-4].

Uma característica diferente na soldagem com arames tubulares é o uso de uma maior extensão do eletrodo, principalmente quando se deseja otimizar o processo para altas taxas de deposição [5]. Nos arames com proteção gasosa limita-se o uso de grandes extensões de eletrodo devido à proteção do gás que pode ficar prejudicada. Recomenda-se valores entre 19 e 38 mm [6].

A taxa de deposição é influenciada, tanto no arame maciço como no arame tubular, pela densidade de corrente, com o arame tubular possuindo uma maior densidade de corrente que o arame maciço, para uma mesma bitola de arame [7].

Os dois processos diferem com relação ao tipo de transferência metálica [1,5-11]. A Tabela 1 mostra os diferentes processos de soldagem por fusão e os modos de transferência de gotas líquidas metálicas, segundo as referências [8] e [9]. Esta tabela foi atualizada com relação a novos desenvolvimentos.

Na soldagem com arame maciço podem-se ter diferentes modos de transferência como: globular, curto-circuito, spray (axial e rotacional) e projetado (para a soldagem com arco pulsado), dependo dos parâmetros de soldagem e do tipo de gás utilizado. No processo de soldagem com arame tubular a transferência é guiada pela escória, combinada com a transferência globular e por explosão. Desta maneira, as variáveis dos processos de soldagem estudadas afetam de maneira diferente a fusão dos dois tipos de consumíveis utilizados.

O destacamento das gotas é função da intensidade das forças que atuam na mesma no momento de destacamento. A Figura 1 apresenta, esquematicamente, a ação destas forças na soldagem com eletrodo revestido,

Tabela 1. Tipos de transferências de gotas líquidas metálicas em função dos processos de soldagem e segundo a classificação do IIW. Adaptado das ref. [8,9].

\section{1 - TRANSFERÊNCIA POR VÔO LIVRE}

\section{1 - Transferência Globular}

\subsubsection{Transferência por gotas}

1.1.2 Transferência por repulsão

1.2 - Transferência por Spray (não aplicável para gás hélio e para misturas hélio-argônio com mais de $25 \% \mathrm{He}$ e misturas argônio e $\mathrm{CO} 2$ com mais de $25 \%$ de $\mathrm{CO} 2$ na mistura gasosa)

1.2.1 Spray projetado

1.2.2 Spray axial

1.2.3 Spray rotacional

1.3 - Transferência por Explosão

\section{TRANSFERÊNCIA POR CONTATO}

\section{1 - Transf. por Curto-Circuito}

2.2 - Transferência Contínua

3. TRANSFERÊNCIA GUIADA POR ESCÓRIA

\section{1 - Transferência guiada pela parede de fluxo líquido}

3.2 - Outros modos
MIG/MAG(GMAW) com baixa corrente, AT(FCAW autoprotegido, com proteção gasosa e com alma metálica)

MIG/MAG(GMAW) com $\mathrm{CO}_{2}$ como gás de proteção; AT(FCAW auto-protegido, com proteção gasosa e com alma metálica)

MIG/MAG(GMAW) - corrente pulsada

MIG/MAG(GMAW) - corrente intermediária

MIG/MAG(GMAW) - corrente elevada

ER(SMAW), MIG/MAG (GMAW) para alumínio e aço inoxidável, AT(FCAW auto-protegido, com proteção gasosa e com alma metálica)

MIG/MAG(GMAW) - curto circuito; ER(SMAW).

TIG (GTAW) com adição de metal, Oxigás com adição

AS(SAW)

ER(SMAW), AT(FCAW auto-protegido e com proteção gasosa), Eletro-escória (ESW) 


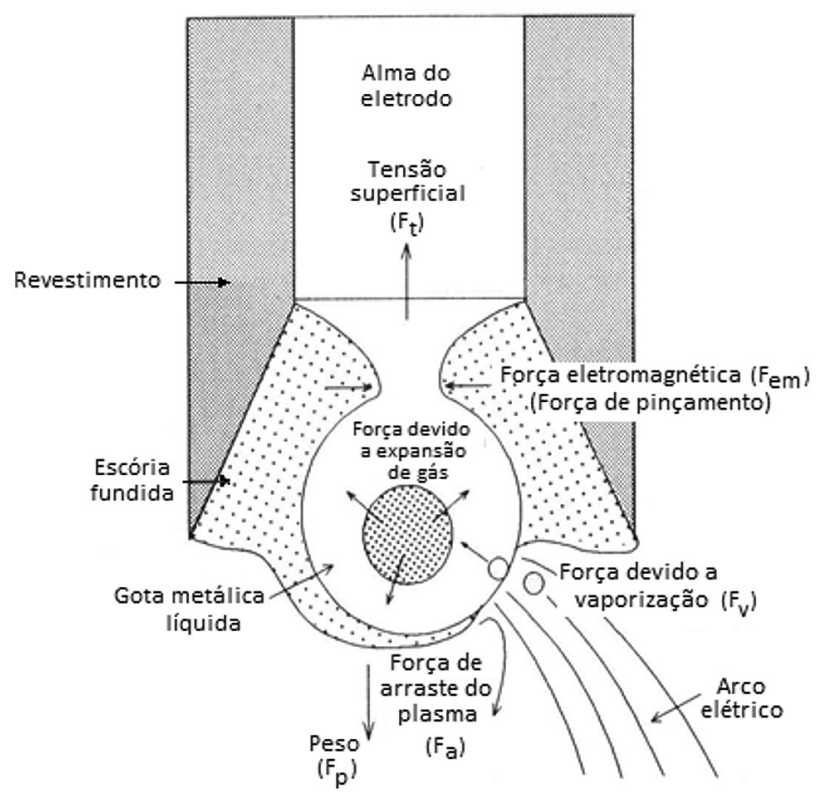

Figura 1. Esquema das forças que podem atuar na transferência de uma gota metálica na soldagem com eletrodo revestido [5].

que é um processo que pode ter todos os tipos de forças atuantes em processos de soldagem que envolvem a transferência de gotas metálicas líquidas.

Estas forças possuem equações simplificadas, propostas por Lancaster [11], que mostram o efeito das variáveis de soldagem na intensidade destas forças. Das forças apresentadas, algumas atrasam o destacamento como a tensão superficial gota/arame, tensão superficial gota/escória líquida, força devido a vaporização, a força peso (dependendo da posição de soldagem) e a força eletromagnética (dependendo da polaridade do consumível). Outras favorecem o destacamento, como a força devido ao arraste de plasma, a componente de pinçamento da força eletromagnética, a componente da força eletromagnética associada a polaridade e a força peso (dependendo da posição de soldagem). A seguir são mostradas as equações de cada uma destas forças.

A força peso $\left(\mathrm{F}_{\mathrm{p}}\right)$, Equação 1, está relacionada com o volume da gota e sua atração pelo campo gravitacional. $\mathrm{Na}$ Equação 1 o r representa o raio da gota líquida, $\rho$ representa a densidade da gota líquida e $\mathrm{g}$ a aceleração da gravidade. Quanto maior o tamanho da gota, maior a força peso.

$$
\mathrm{F}_{\mathrm{p}}=\frac{4}{3} \pi \mathrm{r}_{\mathrm{gota}}^{3} \rho \mathrm{g}
$$

A força devido a tensão superficial $\left(F_{t}\right)$, Equação 2, atua no perímetro de contato entre a gota e a alma metálica. Quanto maior o raio do arame, maior a tensão superficial gota líquida/alma. Da mesma maneira, a tensão superficial entre a escória líquida e a gota líquida também tem efeito no atraso do destacamento da gota, em particular devido a grande diferença de viscosidade entre o metal líquido e a escória líquida. Na equação, está representada a força devido a tensão superficial em função do raio da alma (arame maciço) em função da tensão superficial metal sólido/metal líquido $\left(\gamma_{\text {metal sólido/metal líquido }}\right)$.

$$
\mathrm{F}_{\mathrm{t}}=2 \pi \mathrm{r}_{\mathrm{alma}} \gamma_{\text {metal sólido/metal liquido }}
$$

A força de origem eletromagnética, Equação 3, tem duas componentes. A componente que age na horizontal é chamada de força de pinçamento, que sempre atua no sentido de destacar a gota. Já a outra componente atua, dependendo da área de entrada da corrente e entre a área de saída da mesma (área da parte metálica do consumível), que é função da área de contato entre o arco elétrico e a gota líquida [11]. No caso da polaridade direta 
(eletrodo negativo), está área de contato é menor que a área da gota por onde flui a corrente, e a componente da força eletromagnética na vertical, age no sentido contrário ao destacamento da gota. Por outro lado, na polaridade reversa (eletrodo no positivo) a situação se inverte e a componente atua no sentido de acelerar o destacamento da gota. Na Equação 3, f é uma constante adimensional (relaciona o comprimento do condutor de eletricidade pela distância ao ponto de interesse) e I a corrente de soldagem.

$$
\mathrm{F}_{\mathrm{em}}=\mathrm{f}_{1} \frac{\mu_{\mathrm{o}} \mathrm{I}_{\text {soldagem }}^{2}}{4 \pi}
$$

A força devido a vaporização $\left(F_{v}\right)$, Equação 4, ocorre devido a uma reação contrária a vaporização de metal na região da gota, em contato com o arco elétrico. Esta força tende a atrasar a transferência metálica. Na Equação 4 o $Q_{0}$ representa a taxa de vaporização do elemento químico de interesse, I é acorrente de soldagem, $\rho_{\text {vapor }}$ é a densidade do vapor e $\mathrm{R}_{\mathrm{a}}$ a área de contato entre a gota e o arco elétrico. Esta área varia conforme o modo de transferência metálica.

$$
\mathrm{F}_{\mathrm{v}}=\frac{\mathrm{Q}_{0}^{2} \mathrm{I}_{\text {soldagem }}^{2}}{8 \pi \rho_{\text {vapor }} \mathrm{R}_{\mathrm{a}}^{2}}
$$

A equação da força de arraste de plasma, Equação 5, pode ser emprestada da mecânica dos fluidos, através do estudo do arraste de uma esfera em um fluido em movimento, dentro de uma forma cilíndrica. Assumindo o arco elétrico com uma forma cilíndrica, com raio $R_{\text {cilindro }}$ um coeficiente de arraste $C_{d^{\prime}}, \rho_{\text {plasma }}$ a densidade do plasma, $U$ a velocidade do plasma e $r_{\text {gota }}$ o raio da gota que está sendo arrastada pelo plasma. Na Equação 5, a velocidade do plasma é diretamente proporcional à corrente de soldagem.

$$
\mathrm{F}_{\mathrm{a}}=\mathrm{C}_{\mathrm{d}}\left(\rho_{\text {plasma }} \frac{\mathrm{U}^{2}}{2}\right)\left[1-\left(\frac{\mathrm{R}_{\text {plasma }}^{2}}{2 \mathrm{r}_{\text {gota }}^{2}}\right)\right] \pi \mathrm{r}_{\text {gota }}^{2}
$$

Estas são algumas das características que distinguem os processos de soldagem que utilizam estes dois tipos de arames e podem justificar as maiores taxas de deposição do arame tubular. Entretanto, quando se faz uma comparação com o custo de produção entre os dois consumíveis, sólido e tubular com proteção gasosa, pode-se dizer que o arame tubular tem um custo mais elevado na relação custo/peso do metal depositado que o arame maciço [12].

Um estudo feito por Widgery [13], em 1994 na Inglaterra, mostrou altas taxas de deposição alcançadas pelo arame tubular rutílico E71T-1C, seguido pelo arame tubular com núcleo metálico (metal-cored) e pelo arame maciço (MIG/MAG), todos com diâmetro de 1,2 mm. Mostrou que, na proporção em que se aumenta a corrente, em fontes de energia convencionais, as taxas de deposição aumentam. As menores taxas de deposição foram obtidas com o arame maciço.

No estudo feito por Leite [14], o arame tubular E70C-6M foi o mais eficiente quando comparado com o arame maciço E 70S-6 e o arame tubular E71T-1C. O E70C-6M apresentou a maior taxa de deposição entre os três arames $(5,56 \mathrm{~kg} / \mathrm{h})$ e o menor tempo de soldagem (3,64 minutos por comprimento da peça soldada).

Este trabalho tem como objetivo comparar dois consumíveis que são bastante competitivos em suas aplicações no que diz respeito ao quesito produtividade. Um deles é o arame de solda AWS A5.18 ER70S-6, um arame maciço muito usado na indústria automotiva. O outro, o arame AWS A5.20 E71T-1C, um arame tubular cujas aplicações são as mesmas do arame maciço citado anteriormente. Neste trabalho foi estudada a influência na taxa de deposição, eficiência de deposição, frequência de destacamento da gota, diâmetro teórico da gota e formato do cordão utilizando-se os dois tipos de arame em situações muito comuns na indústria, empregando-se fontes de energia convencionais, correntes entre 200 e 250 A, gases de proteção 100\% $\mathrm{CO}_{2}$ e mistura $75 \% \mathrm{Ar}-25 \%$ $\mathrm{CO}_{2}$ e distâncias do bico de contato à peça de 12 e $20 \mathrm{~mm}$. 


\section{Materiais e Métodos}

A chapa de aço utilizada como metal de base foi ASTM A36 com 8,0 mm de espessura. Cada experimento utilizou uma chapa com 100,0 mm de largura e $300,0 \mathrm{~mm}$ de comprimento. A Tabela 2 apresenta a análise química do certificado do aço utilizado no experimento.

Neste trabalho foram utilizados dois processos de soldagem, o MIG/MAG e o arame tubular. Os consumíveis utilizados foram o arame maciço cobreado (AWS A5.18 ER70S-6) com diâmetro de 1,2 mm e o arame tubular do tipo rutílico com proteção gasosa (AWS A5.20 E71T-1C) com diâmetro de 1,2 mm. Suas composições químicas são especificadas nas Tabelas 3 e 4, tanto do certificado do fornecedor como da especificação AWS.

A soldagem dos experimentos foi realizada com uma fonte de soldagem convencional de tensão constante e corrente contínua com capacidade para $600 \mathrm{~A}$ e alimentador de arame convencional. A soldagem foi executada com auxílio de um sistema de mecanização linear a fim de manter constante a distância do bico de contato à peça (DBCP) e a velocidade de soldagem. Foram feitas oito combinações distintas das condições operacionais de soldagem com cada tipo de arame. Foram realizados três cordões de solda para cada condição operacional avaliada, dois de um lado e outro no verso da chapa, todos na posição plana. A velocidade de soldagem utilizada foi de $5,0 \mathrm{~mm} /$ segundos para todos os experimentos. A vazão do gás de proteção foi medida no bocal da tocha com fluxômetro e ajustada para uma vazão de $15 \mathrm{l} / \mathrm{min}$ imediatamente antes da soldagem. Para a definição dos parâmetros de soldagem foram tomados como base os parâmetros definidos em outros trabalhos feitos com comparação entre arames sólidos e tubulares e pelas recomendações dos fabricantes dos consumíveis [15]. Assim, para o arame tubular os parâmetros recomendados foram: corrente entre 120 e 300A, DBCP entre 19 e 38 mm e gás de proteção $\mathrm{CO}_{2}$ puro. Já para o arame maciço os parâmetros indicados foram: corrente entre 120 e $380 \mathrm{~A}$, DBCP entre 12 e 20 mm e gás de proteção $\mathrm{CO}_{2}$ puro ou mistura. A Tabela 5 mostra os parâmetros escolhidos com base nestes dados. Nos experimentos a tensão do arco variou entre 28 a $30 \mathrm{~V}$ e 26 a $28 \mathrm{~V}$, respectivamente para o arame maciço e para o arame tubular. As velocidades de alimentação de arame variaram entre 6 a 10 e entre 7 a $12 \mathrm{~m} / \mathrm{min}$, respectivamente para o arame maciço e para o arame tubular.

Tabela 2. Composição Química do aço ASTM A36.

\begin{tabular}{ccccc}
\hline $\mathbf{C}$ & $\mathbf{S i}$ & $\mathbf{M n}$ & $\mathbf{P}$ & $\mathbf{S}$ \\
0,250 & 0,400 & 1,000 & 0,040 & 0,050 \\
\hline
\end{tabular}

Tabela 3. Composição química do arame maciço ER70S-6.

\begin{tabular}{cccccccccccc}
\hline \multicolumn{1}{c}{ Fonte } & $\mathbf{C}$ & $\mathbf{S i}$ & $\mathbf{M n}$ & $\mathbf{P}$ & $\mathbf{S}$ & $\mathbf{N i}$ & $\mathbf{C r}$ & $\mathbf{M o}$ & $\mathbf{V}$ & $\mathbf{C u}$ & Al \\
Certificado & 0,082 & 0,828 & 1,543 & 0,018 & 0,018 & 0,014 & 0,033 & 0 & 0 & 0,022 & 0,0005 \\
Especificação AWS & $0,06-0,15$ & $0,80-1,15$ & $0,04-0,85$ & $\leq 0,025$ & $\leq 0,035$ & $\leq 0,15$ & $\leq 0,15$ & $\leq 0,15$ & $\leq 0,03$ & $\leq 0,5$ & - \\
\hline
\end{tabular}

Tabela 4. Composição química do arame tubular E71T-1C.

\begin{tabular}{lcccccccccc}
\hline \multicolumn{1}{c}{ Fonte } & $\mathbf{C}$ & $\mathbf{S i}$ & $\mathbf{M n}$ & $\mathbf{P}$ & $\mathbf{S}$ & $\mathbf{N i}$ & $\mathbf{C r}$ & $\mathbf{M o}$ & $\mathbf{V}$ & $\mathbf{C u}$ \\
Certificado & 0,05 & 0,58 & 1,23 & 0,016 & 0,013 & 0,03 & 0,04 & 0,01 & 0,02 & 0,01 \\
Especificação AWS & $\leq 0,12$ & $\leq 0,9$ & $\leq 1,75$ & $\leq 0,03$ & $\leq 0,03$ & $\leq 0,5$ & $\leq 0,2$ & $\leq 0,3$ & $\leq 0,08$ & $\leq 0,35$ \\
\hline
\end{tabular}

Tabela 5. Combinações entre as variáveis distância do bico de contato à peça (DBCP), gás de proteção e corrente para cada tipo de arame.

\begin{tabular}{|c|c|c|c|c|c|c|c|c|c|c|c|c|c|c|c|}
\hline $\begin{array}{l}\text { Tipo de } \\
\text { Arame }\end{array}$ & \multicolumn{8}{|c|}{ Arame Maciço } & \multicolumn{7}{|c|}{ Arame Tubular (E71T-1C) } \\
\hline DBCP & \multicolumn{4}{|c|}{$12 \mathrm{~mm}$} & \multicolumn{4}{|c|}{$20 \mathrm{~mm}$} & \multicolumn{4}{|c|}{$12 \mathrm{~mm}$} & \multicolumn{3}{|c|}{$20 \mathrm{~mm}$} \\
\hline $\begin{array}{l}\text { Gás de } \\
\text { Proteção }\end{array}$ & $100^{\circ}$ & $\mathrm{CO}_{2}$ & $\begin{array}{r}75 \% \\
25 \%\end{array}$ & $\begin{array}{l}\mathrm{Ar}+ \\
\mathrm{CO}_{2}\end{array}$ & 100 & $\mathrm{CO}_{2}$ & $\begin{array}{r}75 \% \\
25 \%\end{array}$ & $\begin{array}{l}\mathrm{Ar}+ \\
\mathrm{CO}_{2}\end{array}$ & $100^{\circ}$ & $6 \mathrm{CO}_{2}$ & $\begin{array}{r}75 \% \\
25 \%\end{array}$ & $\begin{array}{l}\mathrm{Ar}+ \\
6 \mathrm{CO}_{2}\end{array}$ & $100^{\circ}$ & $\mathrm{CO}_{2}$ & $\begin{array}{c}75 \% \mathrm{Ar}+ \\
25 \% \mathrm{CO}_{2}\end{array}$ \\
\hline Corrente (A) & 200 & 250 & 200 & 250 & 200 & 250 & 200 & 250 & 200 & 250 & 200 & 250 & 200 & 250 & $200 \quad 250$ \\
\hline
\end{tabular}




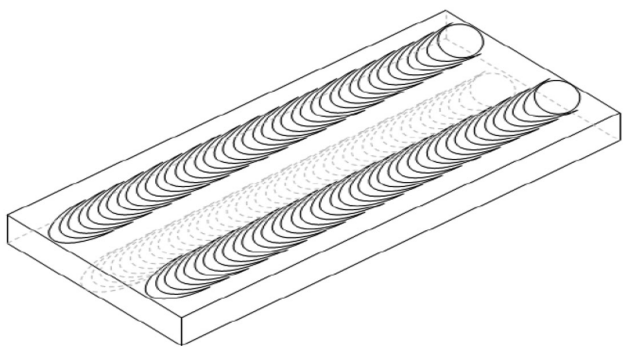

(a)

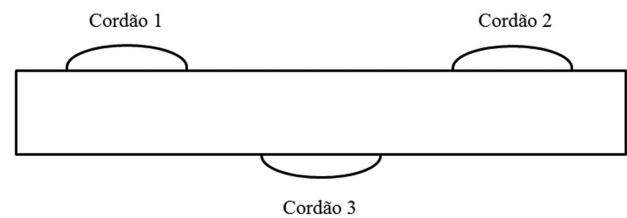

(b)

Figura 2. a) Representação da localização dos cordões de solda em cada chapa. b) Representação da sequência de execução de soldagem em função da localização.

Foram coletados os dados de corrente, tensão e velocidade de alimentação do arame de cada experimento com um Sistema de Aquisição de Dados de Soldagem para análise da taxa de deposição e da eficiência de cada processo. O tempo de aquisição dos dados foi no mínimo de 200 milissegundos.

Em cada chapa de aço ASTM A36 foi realizado três cordões de solda com o mesmo parâmetro. A Figura 2 ilustra o corpo de prova soldado com os três cordões de solda, sendo que dois cordões foram feitos de um lado da chapa e um cordão no lado oposto da mesma. A sequência de execução dos cordões também está representada na Figura 2.

Os cordões feitos com o arame tubular tiveram a remoção da escória feita cuidadosamente para posterior pesagem e a superfície do cordão foi escovada com escova de aço. Após cada cordão e passado de um a dois minutos, tempo suficiente para a limpeza da escória (caso do arame tubular) e destravamento das fixações da chapa na bancada, todos os corpos de prova foram submetidos ao resfriamento com água com o objetivo de prepará-lo para receber o próximo cordão de solda. Este procedimento garantiu que a chapa estivesse sempre na mesma temperatura inicial, $25^{\circ} \mathrm{C}$, antes do início do segundo cordão de solda e antes do último. Após o terceiro cordão de solda a chapa soldada foi resfriada ao ar.

Cada chapa de aço foi seca, após resfriamento com água, pesada e identificada antes da soldagem do segundo e terceiro cordões de solda. Também foram pesados os carretéis de arame antes e depois da soldagem de cada cordão. As pontas de arame e a escória removida foram pesadas numa balança digital com capacidade máxima de $2 \mathrm{~kg}$ e precisão de 0,01 g. Da mesma maneira, os respingos e os silicatos formados foram removidos das chapas, antes da pesagem, para cada experimento e repetição realizados. O tempo de arco aberto foi cronometrado, bem como os comprimentos dos cordões medidos com escala em milímetros.

Para a realização do cálculo da taxa de deposição foi utilizado a Equação 6, segundo as referências [15] e [16].

$$
T_{d}=\frac{M_{f}-M_{i}}{T_{a}}
$$

Onde:

$\mathrm{T}_{\mathrm{d}}=$ Taxa de deposição $(\mathrm{kg} / \mathrm{h})$.

$M_{f}=$ Massa da chapa final $(\mathrm{kg})$.

$\mathrm{M}_{\mathrm{i}}=$ Massa da chapa inicial $(\mathrm{kg})$.

$\mathrm{T}_{\mathrm{a}}=$ Tempo de arco aberto ( $\mathrm{h}$ ).

Para determinação da taxa de deposição foram utilizados os dados coletados durante o experimento. Para a realização do cálculo do diâmetro da gota foi utilizada a Equação 7 e, supondo que a gota tenha um formato esférico, foi calculado o seu diâmetro. A massa da gota foi calculada empregando-se a definição de densidade e utilizando a densidade do aço igual a $7,8 \mathrm{~g} / \mathrm{cm}^{3}$.

$$
V_{\text {gota }}=\frac{\frac{\pi D_{\text {arame }}^{2}}{4} \cdot V_{a l} \cdot T_{a}}{f_{\text {dest }}}
$$


Onde:

$\mathrm{V}_{\text {gota }}=$ Volume da gota $\left(\mathrm{mm}^{3}\right)$

$D_{\text {arame }}=$ Diâmetro do arame $(\mathrm{mm})$

$\mathrm{V}_{\mathrm{al}}=$ Velocidade de alimentação do arame $(\mathrm{mm} / \mathrm{s})$

$\mathrm{T}_{\mathrm{a}}=$ Tempo de arco aberto (s)

$f_{\text {dest }}=$ Frequência de destacamento das gotas $(\mathrm{Hz})$

A frequência de destacamento foi medida a partir do gráfico de tensão fornecido pelo Sistema de Aquisição de Dados de Soldagem da empresa IMC ${ }^{\circ}$. Foi medida a quantidade de vezes que a tensão tendeu a zero e contabilizado como uma gota de metal fundido depositada na poça de fusão, pois foi adotado que quando a tensão apresenta o menor valor há o destacamento da gota de metal fundido. Essa quantidade de gotas destacadas foi dividida pelo tempo de 0,2 segundo e assim obtido a frequência de destacamento com a unidade de gotas por segundo. Este tempo foi escolhido por representar bem o fenômeno estudado e por não produzir um número excessivo de dados experimentais.

A eficiência de deposição foi calculada a partir da razão entre a massa de metal depositado e a massa de arame que foi fundido, através da pesagem da bobina de arame antes e após o experimento.

\section{Resultados e Discussões}

A Tabela 6 apresenta os valores médios das grandezas medidas nos experimentos.

\subsection{Diâmetro da gota}

A Figura 3 mostra os resultados obtidos dos efeitos dos parâmetros estudados no diâmetro da gota calculado teoricamente. Analisando o gráfico da Figura 3a, que representa o efeito principal de cada variável estudada, observa-se a influência que uma maior quantidade de $\mathrm{CO}_{2}$ no gás de proteção produziu um aumento no tamanho médio das gotas. Da mesma maneira, o arame tubular gerou gotas com diâmetro maiores. As reduções de corrente de soldagem e da distância bico de contato à peça (DBCP) aumentam o diâmetro da gota.

O efeito global da composição do gás de proteção pode estar relacionado à ação da força de repulsão que atua na gota durante a sua transferência. Esta força tem efeito mais pronunciado em arcos com gás de proteção de $\mathrm{CO}_{2}$ puro. Ela ajuda a impedir o destacamento da gota, tendo um efeito no aumento do diâmetro da mesma.

Tabela 6. Valores das grandezas medidas nos experimentos.

\begin{tabular}{|c|c|c|c|c|c|c|c|c|}
\hline $\begin{array}{l}\text { Tipo de } \\
\text { consumível }\end{array}$ & Exper. & $\operatorname{DBCP}(\mathrm{cm})$ & $\begin{array}{l}\text { Tipo de } \\
\text { gás }\end{array}$ & $\begin{array}{l}\text { Tensão do } \\
\text { arco } \\
\text { (V) }\end{array}$ & $\begin{array}{c}\text { Corrente } \\
\text { (A) }\end{array}$ & $\begin{array}{l}\text { Potência } \\
\text { do arco } \\
\text { (W) }\end{array}$ & $\begin{array}{l}\text { Veloc. alim. } \\
\text { do arame } \\
\text { (m/min) }\end{array}$ & $\begin{array}{l}\text { Taxa de } \\
\text { deposição } \\
\text { kg/h }\end{array}$ \\
\hline \multirow[t]{8}{*}{ ER70-S6 } & M1 & 12 & \multirow{4}{*}{$\begin{array}{c}75 \mathrm{Ar} / 25 \% \\
\mathrm{CO}_{2}\end{array}$} & 28,0 & 230 & 6440 & 6,9 & 3,72 \\
\hline & M3 & 12 & & 28,0 & 270 & 7560 & 7,9 & 4,76 \\
\hline & M5 & 20 & & 29,0 & 200 & 5800 & 6,8 & 3,85 \\
\hline & M7 & 20 & & 28,5 & 230 & 6555 & 9,3 & 5,17 \\
\hline & M2 & 12 & \multirow[t]{4}{*}{$100 \% \mathrm{CO}_{2}$} & 30,0 & 210 & 6300 & 7,5 & 4,24 \\
\hline & M4 & 12 & & 29,0 & 242 & 7018 & 7,9 & 4,61 \\
\hline & M6 & 20 & & 30,0 & 200 & 6000 & 7,9 & 5,20 \\
\hline & M8 & 20 & & 30,0 & 230 & 6900 & 9,3 & 5,02 \\
\hline \multirow[t]{8}{*}{ E71-T1 } & $\mathrm{T} 1$ & 12 & \multirow{4}{*}{$\begin{array}{c}75 \mathrm{Ar} / 25 \% \\
\mathrm{CO}_{2}\end{array}$} & 27,0 & 213 & 5751 & 8,1 & 3,86 \\
\hline & T3 & 12 & & 25,7 & 247 & 6348 & 9,7 & 4,52 \\
\hline & T5 & 20 & & 27,0 & 190 & 5130 & 7,9 & 3,70 \\
\hline & T7 & 20 & & 26,0 & 220 & 5720 & 11,1 & 5,25 \\
\hline & $\mathrm{T} 2$ & 12 & \multirow[t]{4}{*}{$100 \% \mathrm{CO}_{2}$} & 28,0 & 190 & 5600 & 6,2 & 2,98 \\
\hline & $\mathrm{T} 4$ & 12 & & 26,8 & 257 & 6888 & 12,0 & 5,64 \\
\hline & T6 & 20 & & 25,0 & 200 & 4575 & 8,5 & 4,00 \\
\hline & T8 & 20 & & 25,0 & 250 & 6250 & 12,0 & 5,64 \\
\hline
\end{tabular}




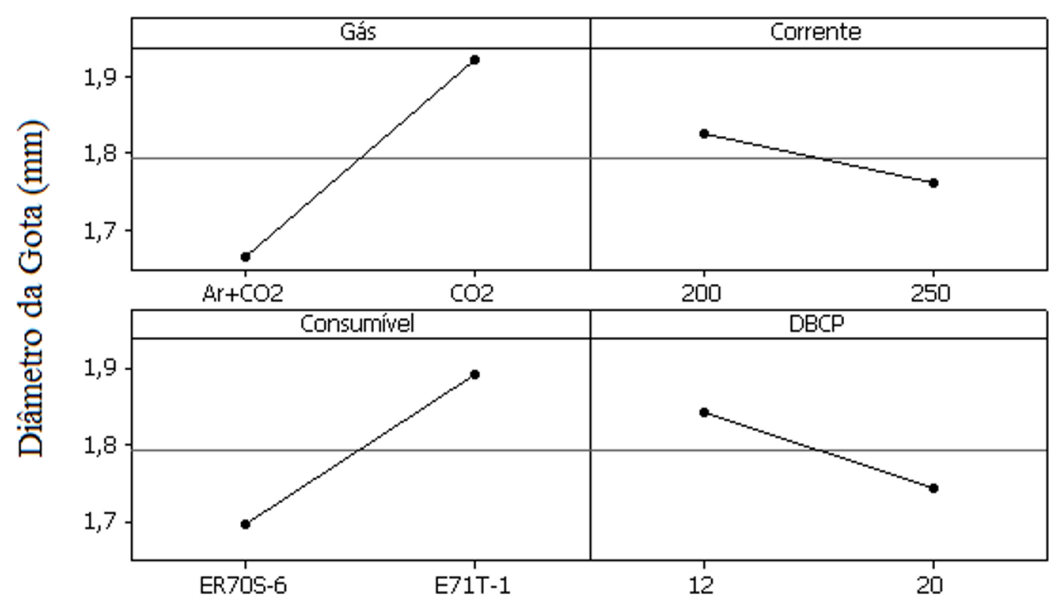

(a)

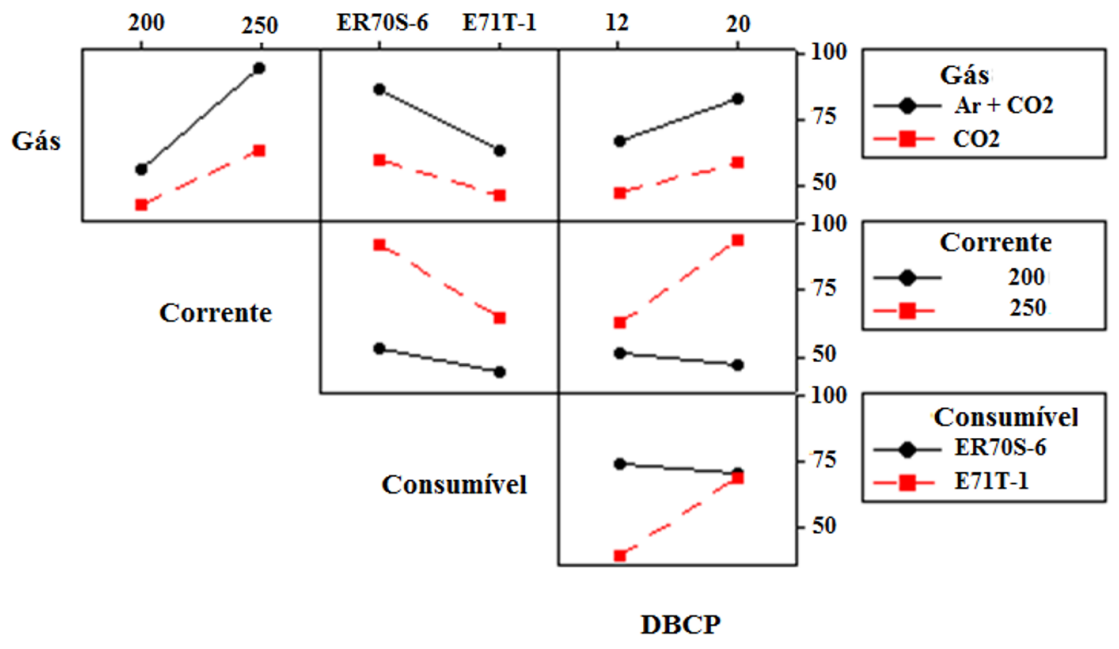

(b)

Figura 3. a) Gráfico dos principais efeitos para o diâmetro da gota. b) Gráfico de interação dos parâmetros de soldagem para o diâmetro da gota.

A redução da corrente de soldagem acarreta um aumento do tamanho da gota. Este efeito pode estar relacionado à componente da força de pinçamento (força eletromagnética), que favorece o destacamento e a redução da densidade de corrente na ponta do consumível, junto ao arco elétrico e com a redução no aquecimento da ponta do arame maciço para promover sua fusão. A força de pinçamento é tanto mais intensa quanto maior for a corrente de soldagem, favorecendo a transferência da gota em tempos menores, isto é, produzindo gotas com tamanhos menores. A redução da corrente produziu gotas com tamanhos maiores, porque gera menor calor por efeito Joule e reduz a taxa de deposição do consumível, além de diminuir a força de pinçamento.

Os consumíveis empregados neste estudo foram o arame maciço e o arame tubular. Cada um deles possui modos de transferência metálica diferentes, com diferentes forças atuando no destacamento da gota e com intensidades diferentes. $\mathrm{O}$ arame maciço, soldando com misturas $\mathrm{Ar}-\mathrm{CO}_{2}$, pode apresentar transferências metálicas que vão do curto-circuito, passando pela globular, projetada e chegando na transferência por spray, dependendo dos parâmetros de soldagem e do tipo de equipamento utilizado, seja com corrente pulsada ou não. O mesmo arame soldando com $\mathrm{CO}_{2}$ puro pode apresentar transferência globular, por curto-circuito ou por repulsão. Já o arame tubular tem transferência metálica guiada pela escória combinada com transferência globular e por repulsão. O efeito da escória no destacamento da gota e a força de repulsão geram uma gota com diâmetro maior. 
Ainda com relação aos consumíveis, um acréscimo na densidade de corrente favorece a sua fusão, aumentando a sua taxa de deposição. Para os consumíveis utilizados, as áreas das partes metálicas dos arames foram 1,13 e 0,76 $\mathrm{mm}^{2}$, respectivamente para o arame maciço e para o arame tubular. Com isso, para uma mesma corrente de soldagem, a densidade de corrente no arame tubular é 67,3\% maior que no arame maciço, embora se deva ter em mente as forças que atuam na transferência metálica dos dois consumíveis. A escória produzida pelo arame tubular tem um efeito determinante no tamanho da gota, e sua viscosidade não está diretamente associada à corrente de soldagem.

O efeito da distância bico de contato à peça (DBCP) está associado ao aquecimento da ponta do arame pelo efeito Joule, que está associado ao comprimento do arame, e pela energia produzida no arco elétrico, que está relacionada com o tipo de gás de proteção e ao tipo de consumível. Um aumento na DBCP causa um aumento na velocidade de alimentação do arame, aumentando a taxa de deposição.

Dentre as quatro variáveis estudadas nota-se que a maior influência no diâmetro da gota pelo efeito das variáveis principais está na quantidade de $\mathrm{CO}_{2}$ no gás de proteção, seguido pela natureza do consumível, ou seja, arame maciço ou arame tubular.

Caso não haja interações significativas entre os parâmetros de soldagem utilizados, a explicação dos efeitos principais das variáveis estudadas representa as tendências observadas dos resultados obtidos. Caso haja interação significativa entre dois parâmetros estudados, esta interação também deve ser examinada, pois pode modificar os resultados obtidos pelos efeitos principais. O gráfico da Figura 3b apresenta todas as interações entre as variáveis estudadas. Caso os dois fatores sejam representados por linhas paralelas, não existe interação entre estes dois fatores. Neste estudo serão desprezadas as interações com linhas não paralelas e com pequenas variações entre os valores obtidos das grandezas estudadas nos dois níveis de interação dos parâmetros em questão. No caso da Figura $2 b$ todos os gráficos apresentados mostram que existe interação entre todos os fatores estudados.

Analisando-se as interações da esquerda para a direita, percebe-se que, em função do gás de proteção o aumento do valor da corrente, de 200 A para 250 A, reduz o diâmetro da gota tanto para o gás de proteção com $100 \%$ de $\mathrm{CO}_{2}$, quanto para a mistura rica em argônio (75\%Ar e $25 \% \mathrm{CO}_{2}$ ). O efeito da corrente está relacionado com as componentes da força de pinçamento à superfície da gota. Uma delas sempre favorece o destacamento da gota e a outra depende da polaridade do processo de soldagem, pode acelerar o destacamento da gota (polaridade reversa) ou atrasar seu destacamento (polaridade direta), reduzindo ou aumentando o diâmetro da gota, respectivamente. Estas componentes são tanto maiores quanto maior for a corrente de soldagem. Por outro lado, o gás com $100 \%$ de $\mathrm{CO}_{2}$ gera gotas maiores que a mistura com menor concentração de $\mathrm{CO}_{2}$, para ambos os valores de corrente estudados. Este resultado está associado à força de repulsão, que se torna mais acentuada quanto maior for a concentração de $\mathrm{CO}_{2}$ no gás de proteção. Este efeito explica o resultado do deslocamento do diâmetro da gota para valores maiores com o gás com $100 \%$ de $\mathrm{CO}_{2}$ apresentado no gráfico da interação corrente e tipo de gás.

Quando se analisa a interação entre o gás de proteção e a natureza do consumível utilizado, nota-se que o diâmetro da gota aumenta quando se muda de arame maciço para arame tubular, mantendo-se a composição do gás de proteção. Quando se muda da mistura $\mathrm{Ar}-25 \% \mathrm{CO}_{2}$ para $100 \%$ de $\mathrm{CO}_{2}$ o diâmetro da gota aumenta pelo efeito da força de repulsão, como discutido anteriormente.

Com relação à interação entre a mistura gasosa e a distância bico de contato à peça (DBCP) nota-se uma redução do diâmetro da gota com o aumento da $\mathrm{DBCP}$, com uma tendência similar à apresentada pelo aumento da corrente. Esse resultado está associado ao aquecimento na ponta do consumível, tanto o aquecimento por efeito Joule como pela energia gerada pelo arco elétrico.

O efeito conjunto da corrente de soldagem com a natureza do consumível estudado mostra que para a corrente menor praticamente não houve alteração no tamanho da gota, para os dois consumíveis utilizados, ER70S-T6 e E71T-1C. Já para a corrente maior o arame maciço apresentou uma gota menor que o arame tubular. Estes resultados podem estar relacionados aos modos de transferência metálica. $\mathrm{O}$ arame maciço apresentou uma redução no tamanho da gota, tendendo ao curto-circuito, porém com gotas menores, devido à ação de uma intensidade de corrente maior. Já o arame tubular tem modo de transferência metálica que é menos afetado pela corrente de soldagem, quando comparados com o arame maciço, por possuir transferência metálica guiada por escória [10]. 
A interação entre a corrente de soldagem e o DBCP apresentou resultados distintos. Quanto a DBCP foi de $12,0 \mathrm{~mm}$, o aumento da corrente causou um aumento no diâmetro da gota, para os dois consumíveis utilizados. Por outro lado, para o valor de 20,0 mm de DBCP, o aumento da corrente produziu uma diminuição no diâmetro da gota. Este resultado está associado ao aquecimento produzido na ponta dos consumíveis e também ao modo de transferência para cada valor de corrente de soldagem, como discutido anteriormente.

A interação consumível e DBCP mostra que o arame tubular apresenta maior diâmetro de gota que o arame maciço, quando se trabalha com um valor de DBCP de 12,0 mm. Caso o valor da DBCP for aumentado para 20,0 mm, os valores de diâmetro da gota são iguais para ambos os consumíveis adotados. O aumento da DBCP causa uma redução da corrente de soldagem e, consequentemente uma redução na densidade de corrente para cada tipo de consumível, tornando o aquecimento por efeito Joule menos importante para a transferência metálica.

\subsection{Frequência de destacamento da gota}

Comparando-se a Figura 4a com a Figura 3a observa-se que o efeito na frequência de destacamento é o inverso do efeito das varáveis no diâmetro da gota. Em outras palavras, as explicações para os efeitos das variáveis

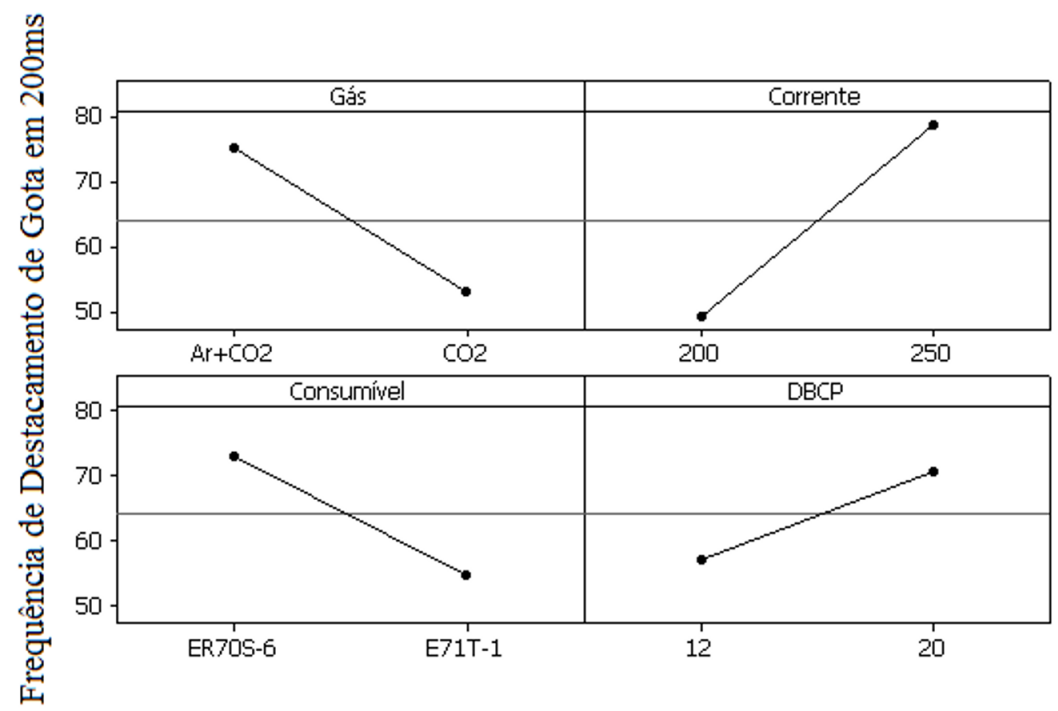

(a)

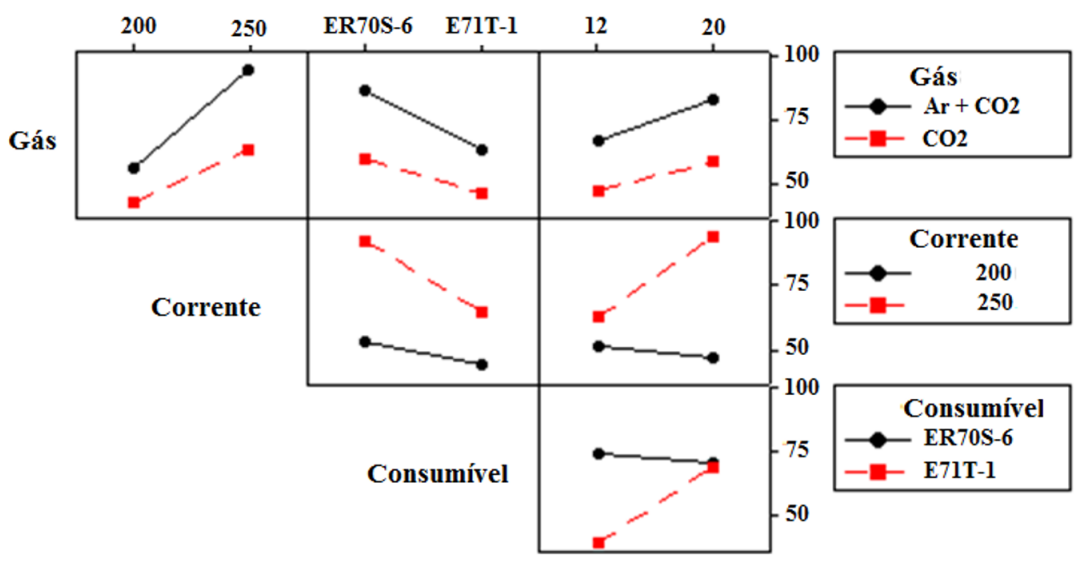

DBCP

(b)

Figura 4. a) Gráfico dos principais efeitos para a frequência de destacamento da gota. b) Gráfico de interação para a frequência de destacamento da gota. 
principais e das interações devem ser procuradas no item 3.1, e feitas as analogias entre as discussões do diâmetro da gota e da frequência de destacamento. Observando-se a Figura 4a, notou-se que a mistura rica em argônio, o arame maciço, o valor de corrente de 250 A e o DBCP de $20,0 \mathrm{~mm}$ aumentaram a frequência de destacamento de gotas de metal líquido. As misturas ricas em argônio podem apresentar a transferência metálica globular ou curto-circuito com gotas menores, devido à redução do efeito da força de repulsão, que aumenta a frequência de destacamento de gotas. $\mathrm{O}$ arame maciço possuiu frequência de destacamento maior que o arame tubular, por apresentar tipo de transferência metálica diferente. Este comportamento do arame maciço é influenciado pelos valores maiores de corrente de soldagem e DBCP.

Analisando as interações na Figura 4b observou-se que a interação entre o gás de proteção e a DBCP não foi significativa. Os resultados experimentais da interação entre o gás de proteção e a corrente de soldagem, mostraram que ocorre um aumento na frequência de destacamento para a mistura gasosa e para a corrente de 250 A. O aumento da frequência de destacamento produz um diâmetro menor da gota. Assim, a explicação para esta interação deve ser análoga à explicação da redução do diâmetro da gota.

O efeito da interação entre o tipo de gás de proteção e o tipo de consumível alterou a frequência de destacamento. A frequência de destacamento é maior para a mistura gasosa e para o arame maciço. Em ambos os casos ocorreu uma diminuição do diâmetro da gota.

O resultado da interação entre a corrente de soldagem e o tipo de consumível produziu um aumento na frequência de destacamento com o aumento da corrente de soldagem e com o arame maciço.

A interação entre a corrente de soldagem e a DBCP mostrou que para $200 \mathrm{~A}$, o aumento na DBCP produz uma redução na frequência de destacamento. Já para a corrente de 250 A, o acréscimo da DBCP gerou um aumento na frequência de destacamento.

O efeito conjunto do tipo de consumível com a DBCP indicou que para a DBCP de 20,0 $\mathrm{mm}$ praticamente não houve alteração na frequência de destacamento para os dois consumíveis. Para a DBCP de $12,0 \mathrm{~mm}$, o arame maciço apresentou uma frequência de destacamento muito maior que o arame tubular. $O$ efeito desta interação é mais pronunciado para o arame tubular.

\subsection{Taxa de deposição}

$\mathrm{Na}$ Figura 5a observa-se que as variáveis individuais que, estatisticamente, provocaram os maiores efeitos sobre a taxa de deposição foram a corrente e a DBCP.

A taxa de deposição foi diretamente proporcional ao aumento da DBCP e da corrente de soldagem. Estas variáveis também aumentaram a frequência de destacamento da gota de metal líquido e reduziram o diâmetro das gotas. Em paralelo, a velocidade de alimentação dos arames também aumentou. Os efeitos de aumentar a frequência de destacamento e diminuir o diâmetro das gotas poderiam se opor e tender a manter a taxa de deposição inalterada. Entretanto, o efeito de aumentar a frequência de destacamento parece ser mais pronunciado, principalmente pelo efeito da corrente, o que certamente leva ao aumento da taxa de deposição verificado. Em outras palavras, para um tempo constante, obteve-se uma maior massa de arame depositado, isto é, aumentou a taxa de deposição.

Na Figura 5b observa-se que a interação tipo de gás e corrente de soldagem e a interação entre consumível e DBCP não foram significativas.

A interação entre gás de proteção e tipo de consumível mostrou que o arame maciço apresenta uma maior taxa de deposição que o arame tubular quando o gás de proteção utilizado for $100 \%$ de $\mathrm{CO}_{2}$. Os valores são comparáveis quando se utilizou misturas ricas em argônio. Este resultado pode ser explicado pela redução do diâmetro da gota e pelo aumento da frequência de destacamento, conforme discutido no item 3.1 deste item.

Ao analisar a interação do gás de proteção com os valores de DBCP, observou-se que o valor de 20,0 mm de DBCP é o que gerou maior taxa de deposição, independente do gás de proteção. Da mesma maneira, o gás com $100 \%$ de $\mathrm{CO}_{2}$ apresentou a tendência de gerar a maior taxa de deposição. Porém, para valores $12,0 \mathrm{~mm}$ da DBCP a diferença entre o tipo de gás é bem menor do que a DBCP com 20,0 mm. 


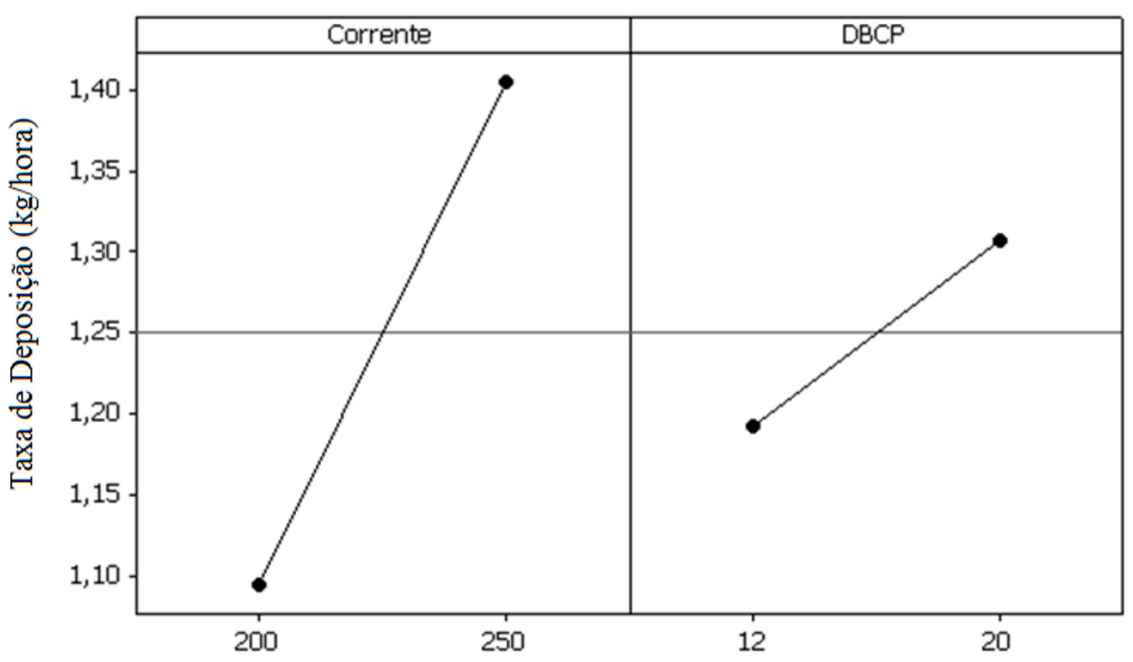

(a)

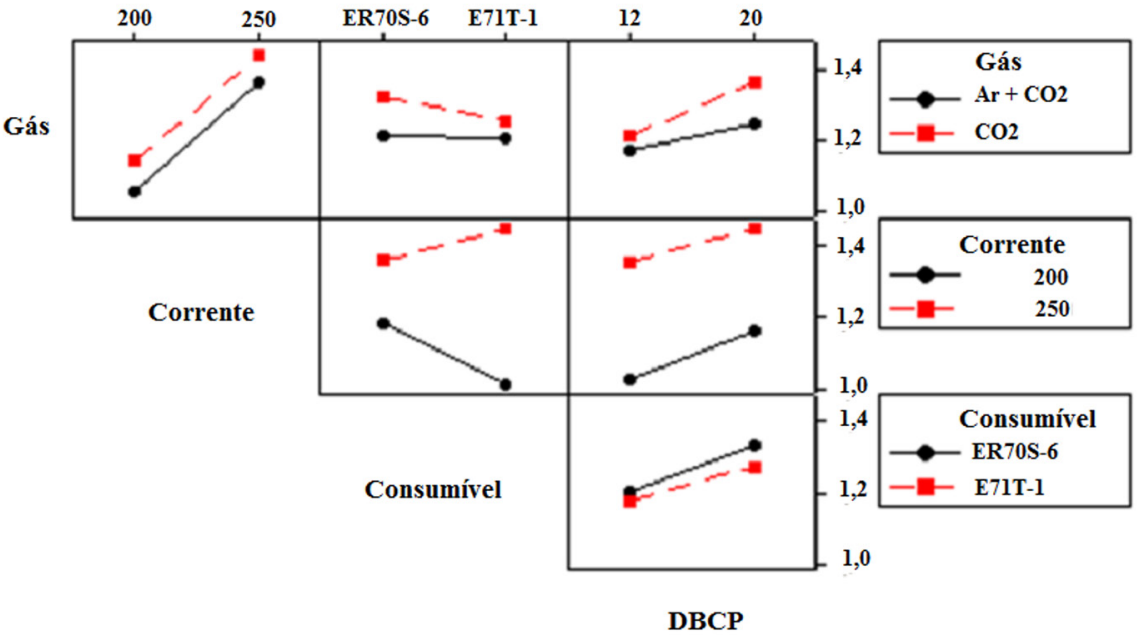

(b)

Figura 5. a) Gráfico dos principais efeitos para a taxa de deposição. b) Gráfico de interação para a taxa de deposição.

Quando se analisa a interação da corrente com o tipo de consumível nota-se que o arame tubular apresentou a maior taxa de deposição para o valor de corrente de 250 A. Quando se analisou a corrente de $200 \mathrm{~A}$, o arame maciço passa a ter maior taxa de deposição. Esse comportamento pode ser explicado pela diferença no modo de transferência dos dois consumíveis.

A interação entre corrente e DBCP mostrou que, para ambos os valores de DBCP, a corrente de 250 A gera uma maior taxa de deposição, assim como, em ambos os valores de corrente, a maior DBCP gerou maior taxa de deposição. A interação entre consumível e DBCP também demonstra que o arame maciço tem a maior taxa de deposição para o valor de 20,0 mm DBCP. A influência do DBCP sobre a taxa de deposição está relacionada à sua influência por efeito Joule.

\subsection{Eficiência de deposição}

Ao analisar a Figura 6a observa-se que apenas o tipo de consumível apresenta grande influência na eficiência de deposição. Neste, o arame maciço apresenta maior eficiência de deposição que o arame tubular. Como a eficiência de deposição é calculada pela massa de metal depositado, sem respingos e escória, pela massa de 


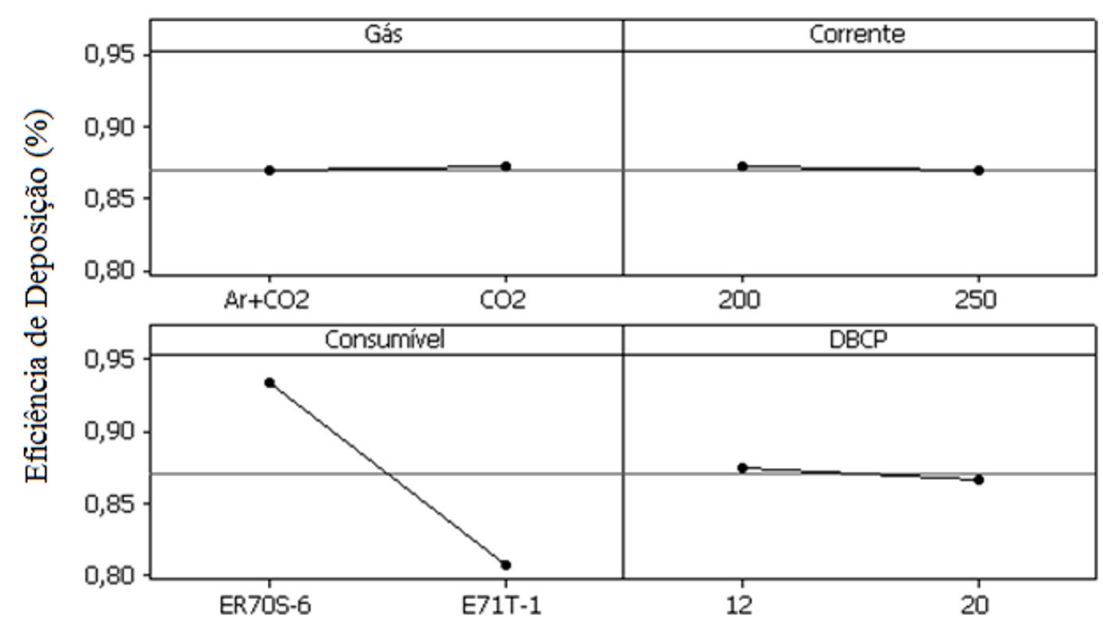

(a)

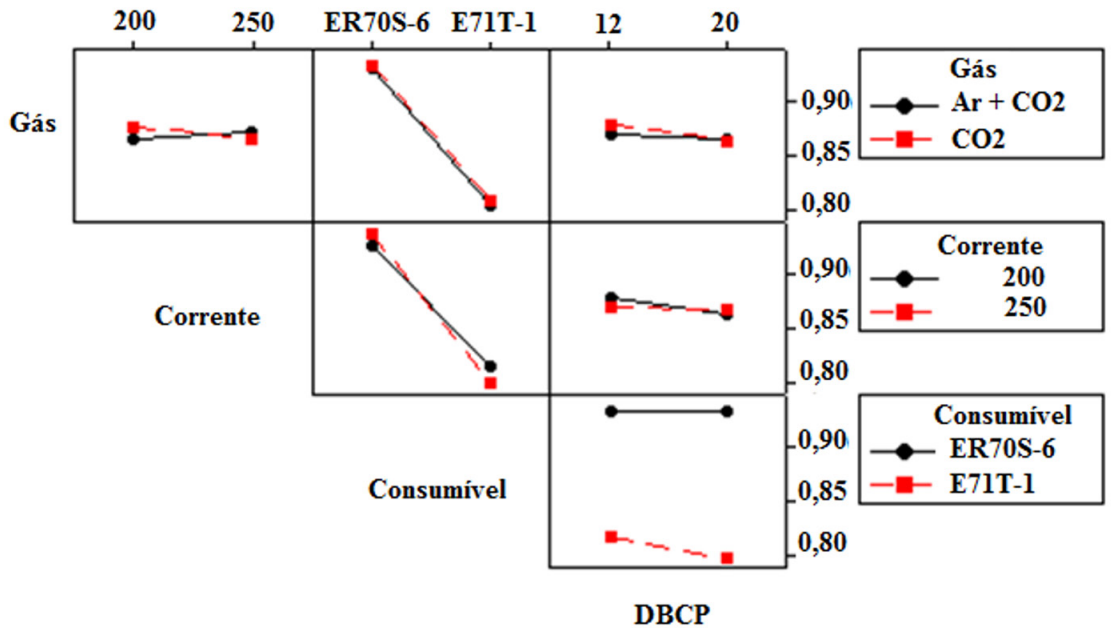

(b)

Figura 6. a) Gráfico dos principais efeitos para a eficiência de deposição. b) Gráfico de interação para a eficiência de deposição.

consumível utilizado, é de se esperar que o arame tubular tenha uma eficiência de deposição menor, porque gera escória, proveniente dos fluxantes do seu interior.

$\mathrm{Na}$ Figura $6 \mathrm{~b}$ nota-se que somente a interação entre o consumível e a DBCP foi significativa. Ao se analisar a interação entre consumível e DBCP, o arame maciço apresenta uma eficiência de deposição superior ao arame tubular. $O$ arame maciço não sofre influência na sua eficiência de deposição com a alteração de 12,0 para 20,0 de DBCP. O arame tubular tende apresentar uma redução na sua eficiência quando se utiliza a DBCP de $20,0 \mathrm{~mm}$. Este efeito pode estar relacionado com o aumento da velocidade de alimentação do arame com o aumento do DBCP.

\section{Conclusões}

Com base nos materiais, parâmetros de soldagem e métodos utilizados foi possível concluir que:

- O tipo de gás de proteção altera o diâmetro da gota e a frequência de destacamento. Ao mudar de gás de proteção com $100 \%$ de $\mathrm{CO}_{2}$ para a mistura gasosa $\mathrm{Ar}+25 \%$ de $\mathrm{CO}_{2}$ tem-se uma redução no diâmetro da gota e um aumento na frequência de destacamento, para os dois consumíveis utilizados. 
- A corrente elétrica é a principal variável para reduzir o diâmetro da gota, aumentar a frequência de destacamento da gota e aumentar a taxa de deposição. Com a mudança de 200 para 250 A, o arame maciço aumenta a sua taxa de deposição em 15\%, enquanto que o arame tubular aumenta em $44 \%$.

- A DBCP é outra variável que influencia no tamanho da gota, na frequência de destacamento e na taxa de deposição. Quando a DBCP é aumentada, diminui o diâmetro da gota, aumenta a frequência de destacamento e aumenta a taxa de deposição.

- O arame maciço ER70S-6 apresenta um diâmetro de gota menor, uma frequência de destacamento maior e uma taxa de deposição maior que o E71T-1C.

- Em média o arame maciço ER70S-6 apresenta uma eficiência de deposição de 93\% e o arame tubular E71T-1C uma eficiência de deposição de $81 \%$.

\section{Agradecimentos}

Os autores agradecem ao Dr. Freddy Poetscher pela ajuda na análise dos resultados das análises estatísticas, à Metalúrgica Atlas pela execução dos experimentos, à empresa Belgo Bekaert Arames pelo suporte na realização deste trabalho fornecendo os consumíveis. O autor J.C.S.J agradece o programa PRH-19 pelo apoio financeiro na forma de bolsa de doutorado.

\section{Referências}

[1] Wainer E, Brandi SD, Melo FDH. Soldagem: processos e metalurgia. São Paulo: Edgar Blucher; 1995. 494 p.

[2] O’Brien RL, editor. AWS Welding Handbook: Welding Process, Vol. 2. 8. ed. Miami: American Welding Society. 1991; 955 p.

[3] Marques PV, Modenesi PJ, Bracarense AQ. Soldagem: fundamentos e tecnologia. 3. ed. Belo Horizonte: Editora UFMG; 2009. 363 p.

[4] Américo S, Ponomarev V. Soldagem MIG/MAG: melhor entendimento, melhor desempenho. São Paulo: Artliber; 2008. $284 \mathrm{p}$.

[5] Brandi SD, Taniguchi C, Liu S. Analysis of metal transfer in shielded metal arc welding. Welding Journal. 1991;70(10):261-270.

[6] Bracarense AQ. Processo de soldagem por arame tubular. In: Universidade Federal de Minas Gerais - UFMG. Apostila UFMG. Belo Horizonte: UFMG; Maio 2000. p. 88-104.

[7] Wang W, Liu S, Jones JE. Flux arc welding: arc signals, processing and metal transfer characterization. Welding Journal. 1995;82(3):369s-377s.

[8] Iordachescu D, Lucas W, Ponomarev V. Reviewing the "Classification of metal transfer". Quebec: IIW; 2006. (International Institute of Welding Document, n. XII-1888-06).

[9] Brandi SD, Taniguchi, C. Análise da transferencia metalica do eletrodo revestido AWS E6013. Soldagem \& Inspeção. 1990;2(3):33-37.
[10] Souza PCRD. Análise da transferência metálica na soldagem com arame tubular [tese de doutorado]. São Paulo: Departamento de Engenharia Metalúrgica e de Materiais, Escola Politécnica da Universidade de São Paulo; 1998.

[11] Lancaster JF. The physics of welding. 2. ed. Oxford: Pergamon Press, International Institute of Welding; 1986. 340 p.

[12] Araújo WR. Comparação entre soldagem robotizada com arame sólido e "metal cored" - a ocorrência do "finger" [dissertação de mestrado]. Belo Horizonte: Universidade Federal de Minas Gerais; 2004.

[13] Widgery D. Tubular wire welding. England: Woodhead Publishing 1994. p. 1-11. http://dx.doi.org/10.1533/9781845698928.1.

[14] Leite FJL. Comparativo de utilização do arame sólido e do arame tubular em junta de topo para chapas ASTM A36 de 6,3 mm de espessura [trabalho de conclusão de curso de especialização]. São Paulo: Universidade de São Paulo; 2012. 139 p.

[15] Garcia RP, Scott A. Uma metodologia para análises comparativas da capacidade produtiva entre arames maciços (MIG/MAG) e tubulares (Eletrodo Tubular). Soldagem \& Inspeção. 2011;16(2):146155. http://dx.doi.org/10.1590/S0104-92242011000200007.

[16] Souza $\mathrm{Cl}$, Ferraresi VA. Análise comparativa dos processos de soldagem GMAW e FCAW com transferência metálica por curto-circuito na posição horizontal. Soldagem \& Inspeção. 2013;18(3):268-280. http://dx.doi.org/10.1590/S010492242013000300009 